\title{
Changing the Face of Education: Computer-Assisted Instruction in the Secondary Education Classroom
}

\author{
Sharvari Tirodkar ${ }^{1}$ and April Lawrence ${ }^{\#}$ \\ ${ }^{1}$ River Hill High School, Clarksville, MD, USA \\ \#Advisor
}

$\underline{\text { ABSTRACT }}$

Researched since the early 1990s, computer-assisted instruction (CAI) continues to prove beneficial for learners across the curriculum. While research has been growing greatly with a focus on higher education, its K-12 education counterpart-specifically secondary education where the use of technology is prevalent-remains largely unexplored. Moreover, as technology advances, students are increasingly exposed to CAI. However, with the rapidly increasing speed of technological advancements, it has become difficult for educational research to progress at the same pace. In light of the COVID-19 pandemic advancing the utilization of instructional technology, it is imperative that all educational stakeholders are introduced to the benefits that CAI can provide: an education that caters to students' learning preferences, equal educational opportunities for all students, and an enhancement of students' motivation in the classroom. With educators more readily integrating technology to support traditional lesson plans, demonstrating its positive impacts on all educational stakeholders can help to alleviate reservations and foster more effective implementation of CAI.

\section{A Review}

Eighty-three percent of students in grades six through twelve claim to use online tools every week to support their schoolwork, according to a 2019 study by Project Tomorrow, a national education nonprofit (Project Tomorrow, 2019). Students who have grown up in the digital age have experienced an increased use of technology in classrooms. However, methods for the implementation of educational technology have not kept pace with technological advancements. Computer-assisted instruction (CAI) can be more effective than exclusively face-to-face instruction in the secondary education classroom because it provides students with a more individualized education, enables disadvantaged and disabled students to more readily access educational opportunities, and increases students' motivation to learn.

The importance of CAI is rooted in students' increasing exposure to better and faster technology as it develops; however, stakeholders in education, including educators, administrators, and parents, may be unaware of the several potential positive effects of CAI. Explaining the benefits of using technology in the classroom to key stakeholders enables CAI to be implemented more effectively, specifically in secondary education classrooms, where the use of educational technology is more prevalent.

As defined by the U.S. Department of Education, CAI is an interactive instructional technique through which educators use technology to present content and monitor student progress. In 2012, a reported 47\% of K-12 educators claimed to utilize multimedia in their classrooms. By 2015 , this number had risen to $68 \%$ of educators (Project Tomorrow, 2016). In just three years, the number of educators using multimedia in the classroom increased by almost forty-five percent, and it is expected to continue to increase with technological developments. Particularly because the COVID-19 pandemic has fostered the enhanced utilization of instructional technology, it has become more important than ever for students and educators to comprehend the depth of potential benefits offered by CAI. Furthermore, 
because they have grown up surrounded by digital devices, students today are more proficient in understanding technology, which should be used to educators' advantage. Students' high digital literacy provides them with the ability to find and evaluate information on digital platforms, enhancing their performance and understanding of the content. Through a meta-analysis of 176 studies regarding online learning, it was concluded that "students in online conditions performed modestly better, on average than those learning the same material through traditional face-to-face instruction," demonstrating that students succeed when they are exposed to digital stimuli (Means et al., 2010, p. xiv). As the primary goal of teaching is to enhance students' understanding of content and prepare them for the challenges of the real world, an environment with technology that caters to students' comforts and needs will undoubtedly enhance academic performance.

Despite CAI improving student performance, the insufficiency of research being conducted on its use in the secondary classroom often leads to fewer educators and parents understanding its benefits and utilizing the technology to help students. While considering the difficulties associated with incorporating CAI into classrooms, it can be observed that "research hasn't been able to keep up with the pace of technological innovation in school." Because of this, it has become increasingly harder to obtain concrete evidence regarding the benefits of technology in schools (Author, personal communication, November 15, 2019). The absence of concrete evidence proves to be a problem because educators do not have access to up-to-date statistics and information on how best to employ technology in their classrooms and better prepare students for a life outside of school. An unexpected finding of the meta-analysis conducted by Means et al. (2010) established "the small number of published studies contrasting online and face-toface learning conditions for K-12 students" (pp. xi-xii). The disparity between technological innovations and educational research results in secondary-level educators remaining unaware of the benefits of CAI, which positively impact a wide range of learners. The need for CAI's implementation in secondary education classrooms is emphasized when considering the importance of educators' ability to observe the perceived advantages of instructional technology and adapt specific technologies to enhance the education their students receive. Implementation would allow educational stakeholders to observe the effects of CAI first-hand and make its benefits more apparent, further improving the quality of a student's education.

Teaching a classroom full of students is a strenuous task; students' various learning preferences and different educational needs make it difficult for a teacher to ensure that all students understand and retain the content to which they are exposed. Ironically, using CAI can enable secondary education teachers to humanize the classroom, implement a personalized system of instruction, and use artificial intelligence (AI) to individualize the education a student receives and accommodate students' different learning needs.

By attempting to accommodate the needs of all students without utilizing technology, teachers may negatively impact their students' education by inadvertently dehumanizing the classroom. A lesson plan meant to teach thirty students may only resonate with the few who are able to follow the method of teaching, as Khan Academy founder Sal Khan suggests, claiming that computer-assisted instruction provides an "obvious benefit." After testing his program on various school districts, Khan (2011) concludes that CAI allows students to learn "by removing the one-size-fits-all lecture from the classroom and letting students have a self-paced lecture," enabling teachers to use technology to ensure all students are participating and reaching their full potential in the classroom. With the utilization of technology, students are encouraged to learn without needing to consider the progress of their peers, allowing students to spend as much or as little time needed to master the curriculum; students who need repeated practice will have additional materials and time available, while students who do not need as much time to focus on a topic are able to move on to more challenging material, all while in the same classroom.

Countless educators currently use multimedia technology in the classroom to allow students to participate in interactive activities. An example of the humanizing effects CAI has on the classroom is shown through the application of Flipgrid, "a threaded video discussion platform" which gives "all students the chance to engage in reflective activities" by allowing the students who do not like speaking out to share what they think anonymously. With digital learning tools, students have the opportunity to "respond from their own space at their own time, so they can process, 
think and practice before responding" (Roshan, 2019, para. 13). Because each student has a different learning personality, some do not like to speak up while others enjoy sharing their thoughts and leading the discussion. With CAI, the quieter students receive the chance to share their opinions without being forced to share when they are not comfortable and confident in their work. Applying CAI humanizes the classroom, as it allows students to interact with each other when they normally would keep to themselves and provides introverted students with an opportunity to build selfconfidence and participate in classroom activities.

Another term associated with CAI is "personalized system of instruction" (PSI). Research has proven PSI, which involves incorporating technology into instruction to allow students to self-pace when mastering content, is an effective method in teaching difficult material that is commonly encountered in secondary classrooms (e.g. Paiva, 2017; Salami, 2007). In a study conducted in secondary education classrooms in Nigeria, chemistry students were split into two groups; one was exposed to PSI whereas the other learned from traditional face-to-face instruction. The results of the study determined that the students who used PSI performed better than the control group because they were required to "take a make-up quiz any time their initial score fell below $90 \%$ correct" and "complete a prior lesson unit before taking a quiz on the succeeding lesson" (Salami, 2007, p. 134). The use of CAI allows students to spend the time that they need on each unit, ensuring that they receive a full understanding of the content, as demonstrated by their performance on the quizzes. They are given the time to review content as needed, taking more quizzes as necessary, ensuring that they are not being held to a timeline by the varying needs and learning speeds of every student in a classroom. Without this individualization of education, students are often forced to move on to the next topic with their peers, even if they have not completely understood preceding topics, making it difficult to comprehend future lessons as they have not mastered fundamental skills.

An additional example of the use of computerized PSI can be found in a study conducted by professors from the Polytechnic Institute of Leiria, Portugal, regarding the use of a tutoring system. The results showed that:

The EG [experimental group] had an average grade significantly higher than CG [control group]. Because the only difference between EG and CG was the restriction on the advance to the next level by the grade not less than $60 \%$ in the formative test... [this] confirms the effectiveness of the ML [mastery learning] rule that the student must achieve the desired level of mastery before progressing to the next level. (Paiva et al., 2017, p. 10)

The established methods of PSI and the controls on students' progression in the course material enabled students to better understand the content and receive higher grades. It is evident that students perform better in their classes if they are taught in a way that best suits their learning needs.

This pedagogical approach, known as "differentiated instruction," has long been utilized by educators. Whether it be in the earliest schoolhouses where students were taught based on their learning preferences and background knowledge, or today where technology allows for the facilitation of instruction designed to meet individual students' needs, "effective teachers have always addressed students' varying needs and interests to help each succeed" (Birnie, 2015, p. 62). Differentiated instruction is advantageous for a student's education in numerous ways, including, the humanization of education as educators are supported in becoming more aware of students' strengths and weaknesses and the increased attention to the skills each student needs to be successful in future classes (Stanford et al., 2010). With computer-assisted instruction allowing for more ease in the implementation of differentiated instruction, students can learn at a self-paced rate and master skills before advancing in the curriculum, enabling the comprehension and mastery of content because their education is tailored to ensure this.

Accompanied by the implementation of CAI, artificial intelligence (AI) is also adapted to perform tasks that teachers may find difficult to accomplish in order to further individualize a student's education. Educators can use artificial intelligence to accomplish tasks that are a part of "the microorganization of human instruction: picking the next exercise for a student to attempt, choosing what sort of hints and feedback to provide, determining when material should be reviewed, and selecting among teaching activities." These responsibilities for teachers "are decisions which 
occur on a granularity that human instructors are typically unable to monitor and individualize" (Mozer et al., 2019, para. 2). Using artificial intelligence to assign tasks allows for necessary repeated practice when it is predicted to be most effective, fostering the ideology that students who have repeated practice with smaller intervals between review times tend to perform better. Utilizing the benefits of AI can unburden teachers from creating a lesson plan that may not impact each student in the same way, while providing more time for teachers to work one-on-one with students to address weaknesses.

AI can also alleviate the struggle to account for students' individual learning needs in current methods of education that only involve face-to-face instruction struggle to account for students' individual learning needs. "While learners bring different experiences, goals, and backgrounds, the current schooling system struggles to offer individualized learning paths" (Roll \& Wylie, 2016, p. 591). With AI, such burdensome problems educators face can be readily resolved, as the technology will take into consideration the needs of each student. Whether AI is used to assign tasks or simply aid the instructor, its benefits alter student learning dramatically. It can assist in increasing the complexity of course material, depending on the student's understanding of previous topics, and enable students to meet personalized learning goals.

Stakeholders assume that there are more negative impacts than benefits to computer-assisted instruction in the classroom. However, such a belief is misconstrued from the idea that devices hinder education. CAI can humanize education by accounting for students' various learning preferences through a personalized system of instruction or, with the help of AI, providing students with the opportunity to review course material as needed. While applying CAI to secondary education classrooms can be a difficult task, accomplishing this necessary step will greatly enhance education.

Factors beyond educators' control lead to students receiving varying educational opportunities; several student groups are considered disadvantaged in terms of the opportunities available to them. Incorporating computerassisted instruction into the secondary classroom has the potential to "level the playing field" for students who have fewer choices in terms of their education. Students living in rural areas, students at risk of not graduating, and students with learning disabilities can all benefit from the implementation of CAI in secondary education classrooms.

Students living in rural areas do not necessarily have the same opportunities in schools, as compared to students living in suburban and urban areas, because of lower populations and lack of demand for certain classes (Author, personal communication, November 15, 2019). With the use of CAI, higher-level, personalized classes can be made available to students in rural communities, even when classes are in low demand. The Amarillo Independent School District in Texas established the "Gateway to Health Careers Project," providing students "from eleven rural districts in the Texas panhandle unique opportunities to learn about careers in the health sciences through blended learning combining online learning and clinical experience." The program, hosted at the Amarillo Area Center for Advanced Learning (AACAL), has seen promising results, "serving a little over 600 students in 24 schools in their rural partner districts" as of Fall 2019 (Digital Learning Collaborative, 2019, p. 29). With the AACAL program, students are exposed to health science careers they may not have encountered in their respective rural communities. These experiences introduce students to various career prospects and inspire them to pursue these careers after completing high school.

Moreover, students living in rural areas often do not have access to the same higher-level courses as their suburban and urban peers. Another example of CAI assisting those in rural areas can be found with a "virtual school for students in Virginia," created "primarily to help provide opportunities where they didn't otherwise exist" (Author, personal communication, November 15, 2019). CAI was employed to offer AP level classes to students who do not have the classes in their school or a teacher who can teach them, such as in southwest rural Virginia. There are many regions where student demand for more college-level courses is low, hindering students from being able to take the advanced-level courses they may need to further prepare them to accomplish their post-secondary plans. Although most people mistakenly believe that only those with stable access to technology and the ability to use the technology correctly will benefit, rural students who do not have guaranteed access can also take advantage of CAI. School systems such as the Amarillo Independent School District in Texas and those in rural Virginia are working to ensure that 
disadvantaged students gain access to educational opportunities and enabling these students to reap the benefits of CAI.

Students who are at risk of not graduating are another group whose education may be improved from the opportunities that CAI provides. The negative stereotypes associated with at-risk students, including their perceived inability to focus and perform well in school, result in a greater likelihood of receiving punishments in school including suspensions and detentions. At-risk students, those who have a high probability to fail academically and drop out before high school graduation due to various circumstances in their home or school environment, face many obstacles in their academic careers. Fortunately, districts are working to help students combat these obstacles. An example of a CAI program working to assist at-risk students can be found in the Bellevue School District in Washington, where:

Eighty-two percent of black and Latino students graduated on time in 2018 — that's 10\% lower than the district's white students and 12\% lower than its Asian students... 56\% of black students and 53\% of Latino students who graduated in 2017 enrolled in college compared to $76 \%$ of white students and $89 \%$ of Asian students. (Digital Learning Collaborative, 2019, p. 31)

To combat these glaring differences between students of different races, the district has established a digital learning program titled RISE. In hopes of fighting inequity and closing the achievement gap, the RISE program ensures that students who have been suspended for more than ten days are keeping up with their classes with the use of digital learning to provide course materials to these students. With CAI initiatives, students can be reprimanded if necessary, while also ensuring that their learning is not hindered.

Traditional methods of face-to-face learning are often unable to provide the support and personalized resources some students need to complete their secondary education. This absence of support "especially impacts atrisk students who are often placed in non-interactive roles of learning where they receive information mostly from lectures and text and often fail to develop sufficient understanding of the content" (Checho, 2007, p. 11). Computerassisted instruction in the classroom can offer some students the reinforcement they need to perform well in school; teachers alone cannot guarantee this level of individualized attention because of the unequal student-teacher ratio. With CAI, instructional cues that at-risk learners need can be provided, potentially allowing them to increase their performance in classes and understand the content, leading to increased retention and improved grades. Additionally, with the opportunities to make up previously failed courses through credit recovery, at-risk students receive supplemental chances to ensure that they graduate on time. As a result, at-risk students will be able to access the individualized education they need, encouraging them to graduate high school.

Students with learning disabilities are a third group of students who may receive benefits from computerassisted instruction, as they do not always have access to the resources needed for academic success. With the use of educational technology, such resources, including appropriately formatted reading materials and accessible assignments, can be made readily available to students. An example of a successful initiative utilizing instructional technology to provide opportunities for students with disabilities is the Santa Clara Unified School District in California, which has created a dual-enrollment program with Mission Community College to provide instructional materials that support disabled students' learning needs. Students who have trouble reading print are presented with digital reading assignments. Software applications and assistive technology are given to these students with the hope that they are encouraged to progress and perform well in their classes while receiving college credits and working towards college degrees. Between 2009 and 2013, 100\% of students in the program planned to pursue higher education, as opposed to the $47.3 \%$ of all students with learning disabilities attending postsecondary education in U.S. institutions in 2009, demonstrating the program's success (Yudin, 2013; Newman et al., 2009). Because students with learning disabilities do not have access to the resources they need, they consequently, are less likely to have the motivation to do well in school, leading to higher dropout rates. Individuals with learning disabilities tend to fall behind their peers, even though the only obstacle preventing them from achieving success is a shortage of user-friendly materials. 
The implementation of CAI can meet students' learning needs and inspire them to meet higher standards, ensuring a successful academic career. Dr. Kerrigan Mahoney, a research associate at the University of Virginia points out that "a lot of kids struggle with reading, and some of that is due to disabilities, like dyslexia." However, "just because the kids have trouble with physically reading the words on the page doesn't necessarily mean that they can't have a high level of the interpretation and understanding of the ideas behind the work" (personal communication, December 16, 2019). Technologies such as audiobooks, podcasts, or radio plays can be used to give students access to books that they cannot read. With access to materials suited for their learning needs, students with learning disabilities may be able to participate in class alongside their peers and perform at the same level. CAI helps to facilitate such opportunities for students with disabilities. Using technology to improve the classroom experience for those with reading disabilities can break barriers for these students and enable them to perform to their highest potential in the same environment as their peers.

Ensuring that disadvantaged students receive equal educational opportunities is important as a proper education reduces the dropout rate of high school students and prepares them for a successful future. The implementation of computer-assisted instruction in secondary classrooms can ensure that disadvantaged students receive the support they need, encouraging them to perform well and graduate high school. Students living in rural areas can be positively affected by the use of CAI because it exposes them to classes that are not otherwise available because of lower student populations and demand. CAI can enable at-risk students to stay on track with their schoolwork and receive the assistance that they need to graduate with their peers. Students with learning disabilities also benefit from the use of CAI because it supplies these students with the tools they need to easily access the course material. Although the effects of CAI can provide increased educational opportunities for everyone, its benefits are emphasized when concerning the accommodation of the learning needs of disadvantaged students.

In addition to individualizing education and equalizing educational opportunities, CAI can be used in the secondary education classroom to increase a student's motivation to learn. Student motivation can be defined as patterns of behavior and effect. With outside factors such as the level of help a student receives and the way the instructor manages the classroom and student involvement, students have the potential to develop their self-confidence, which presents as intrinsic motivation to comprehend content (Seifert, 2010). Computer-assisted instruction in the secondary education classroom can increase a student's motivation to learn in various subject areas, leading to improved student performance.

Educational technology can be incorporated into classrooms across the curriculum, positively impacting a student's motivation. Specifically, regarding second-language acquisition and mathematics education, the use of CAI in these classrooms can stimulate students' desire to learn. In language-learning classrooms, the use of CAI promotes independence and encourages students to keep learning outside of the classroom with the use of engaging, stimulating, and interactive instructional activities (Kritsonis \& Lai, 2006). Using technological tools as at-home materials also allows teachers to spend more time in the classroom focusing on aspects of language learning such as pronunciation and dialogue, which require face-to-face methods of teaching. Such methods enable language students to become well-rounded in their studies and make the path to second-language acquisition an easier one. With regard to the impact of CAI in math classrooms, studies have concluded that technology and multimedia have:

The potential to produce interactive, real-world learning opportunities for students. Through the use of such innovative learning platforms, students are provided relevant experiences that extend outside of the classroom walls to ensure student motivation and learning is supported with the use of technology. (Estapa \& Nadolny, 2015 , p. 46)

With the use of AI to assign problems to students as necessary, technology in math education provides the hands-on experiences students need to remain engaged, as motivation and the desire to learn are dependent on classroom experiences. Therefore, in an environment where students are comfortable, such as a classroom in which the technology 
they have grown up with is prevalent, student engagement is increased, demonstrating higher student motivation and increased performance in secondary education classrooms, where more advanced levels of mathematics are taught.

The current generation of students is growing up alongside technological advancements and increasing their comfort with using technology in everyday tasks. Fostering this preference for the utilization of technology leads to better comprehension and performance. According to an article published in the Journal of College Teaching and Learning, "multimedia allows students and instructors to become engaged in their learning, increase comprehension of abstract concepts, and increase interest and motivation" (Courts \& Tucker, 2012, p. 125). Educators can implement CAI with the use of presentation tools, communication methods, and interactive simulations, allowing students to complete their work and teachers to monitor student progress. With the motivation to accomplish educational tasks, students are more likely to engage in the assignment and put additional effort in when completing it. If a student enjoys learning the material that he or she is exposed to, the student will want to learn more about the content, which benefits his or her learning and behavior and affects the student's choices when achieving a certain goal. With the assistance of CAI, students who exercise increased effort and energy when pursuing a task will improve their persistence, encouraging them to take on more difficult assignments.

Computer-assisted instruction in specific subject areas such as second-language acquisition and mathematics education enables students to encounter real-world experiences and keeps students engaged with interactive activities, fostering their academic growth. In an environment that is tailored to their needs, students are more likely to engage in lessons, increasing their energy when taking on certain tasks. With this increased energy, students will be able to persevere through more difficult tasks, thereby improving their performance on assessments and other assignments.

Implementing computer-assisted instruction in the secondary education classroom provides students with a more effective education than the sole use of face-to-face instruction. Although advancements in technology outpace the growth of educational research, educational stakeholders should consider the positive impacts of technology in the classroom. Both educators and students benefit greatly when educational technology is used, as students can receive a more individualized education, which educators alone cannot necessarily guarantee in a traditional classroom environment. All students will receive more educational opportunities, but CAI can tremendously benefit those with disadvantages compared to the majority of students. Moreover, computer-assisted instruction keeps students engaged in what they are learning in a variety of subjects, increasing their motivation to complete tasks and perform well in school. To ensure that these advantages are well-known, secondary schools should consider implementing computerassisted instruction in their classrooms. The use of CAI is not intended to replace the role that educators play in the classroom, but instead offer additional tools and resources which teachers can incorporate into lesson plans to accommodate students' various learning needs. With the increased efforts to ensure that all students receive access to educational technology, educators and students can discover first-hand how beneficial the use of multimedia in the classroom can be. The numerous benefits provided by CAI in secondary classrooms for both students and educators make it imperative that it is implemented. Not only will embracing computer-assisted instruction strengthen the instruction students receive while engaging in distance and hybrid learning during a global pandemic, but it will facilitate the development of the technology's performance, which will undoubtedly be utilized by future generations.

\section{Acknowledgments}

I would like to thank my advisor April Lawrence for helping me with this project.

\section{References}

Birnie, B. F. (2015). Making the Case for Differentiation. Clearing House: A Journal of Educational Strategies, Issues and Ideas, 88(2), 62-65. https://doi.org/10.1080/00098655.2014.998601 
Checho, C. (2007, December). The Effects of Podcasting on Learning and Motivation: A Mixed Method Study of AtRisk High School Students. https://search.proquest.com/openview/6fcb7cd47faadc0d64886b8c29159631/1?pqorigsite $=$ gscholar $\& \mathrm{cbl}=18750 \&$ diss $=\mathrm{y}$

Courts, B., \& Tucker, J. (2012). Using Technology To Create A Dynamic Classroom Experience. Journal of College Teaching \& Learning (TLC), 9(2), 121-128. https://doi.org/10.19030/tlc.v9i2.6907

Digital Learning Collaborative. (2019). Snapshot 2019- A Review of K-12 Online, Blended, and Digital Learning (Keeping Pace With Digital Learning, pp. 29, 31, 35-37). https://static1.squarespace.com/static/59381b9a17bffc68bf625df4/t/5ce7e6a0eb393130e706bcdc/15587017 30458/DLC-KP-Snapshot2019 052319-a.pdf

Estapa, A., \& Nadolny, L. (2015). The Effect of an Augmented Reality Enhanced Mathematics Lesson on Student Achievement and Motivation. Journal of STEM Education, 16(3), 41-47. https://www.learntechlib.org/p/151963/

Khan, S. (2011, March). Let's use video to reinvent education. https://www.ted.com/talks/salman khan let s use video to reinvent education

Kritsonis, W. A., \& Lai, C.-C. (2006). The Advantages and Disadvantages of Computer Technology in Second Language Acquisition. National Journal for Publishing and Mentoring Doctoral Student Research, 3(1). https://files.eric.ed.gov/fulltext/ED492159.pdf

Means, B., Toyama, Y., Murphy, R., Bakia, M., \& Jones, K. (2010). Evaluation of Evidence-Based Practices in Online Learning: A Meta-Analysis and Review of Online Learning Studies. U.S. Department of Education. https://www2.ed.gov/rschstat/eval/tech/evidence-based-practices/finalreport.pdf

Mozer, M. C., Wiseheart, M., \& Novikoff, T. P. (2019). Artificial intelligence to support human instruction. Proceedings of the National Academy of Sciences of the United States of America, 116(10), 3953-3955. https://doi.org/10.1073/pnas.1900370116

Newman, L., Wagner, M., Cameto, R., Knokey, A.-M., Buckley, J. A., \& Malouf, D. (2009). The Post-High School Outcomes of Youth With Disabilities up to 4 Years After High School A Report From the National Longitudinal Transition Study-2 (NLTS2). National Center for Special Education Research Institute of Education Sciences. https://nlts2.sri.com/reports/2009 04/nlts2 report 200904 complete.pdf

Paiva, R. C., Ferreira, M. S., \& Frade, M. M. (2017). Intelligent tutorial system based on personalized system of instruction to teach or remind mathematical concepts. Journal of Computer Assisted Learning, 33(4), 370381. https://doi.org/10.1111/jcal.12186

Project Tomorrow. (2016). From print to pixel: The role of videos, games, animations, and simulations within K-12 education. Speak Up. https://tomorrow.org/speakup/pdfs/speakup-2015-from-print-to-pixel-may-2016.pdf

Project Tomorrow. (2019). Digital Learning: Peril or Promise for Our K-12 Students. Speak Up. https://tomorrow.org/Speakup/speakup2018-19-Digital-Learning-Peril-or-Promise-october2019.html 
Roll, I., \& Wylie, R. (2016). Evolution and Revolution in Artificial Intelligence in Education. International Journal of Artificial Intelligence in Education, 26(2), 582-599. https://doi.org/10.1007/s40593-016-0110-3

Roshan, S. (2019, January 23). 3 unexpected ways tech can humanize learning | ISTE. International Society for Technology in Education. https://www.iste.org/explore/Personalized-learning/3-unexpected-ways-tech-canhumanize-learning

Salami, S. O. (2007). Effects of Personalised System of Instruction on Students' Academic Achievement in Chemistry. MedWell Journals, 4(1), 132-136. http://docsdrive.com/pdfs/medwelljournals/pjssci/2007/132136.pdf

Seifert, T. (2010). Understanding Student Motivation. Educational Research, 46(2), 137-149. https://doi.org/10.1080/0013188042000222421

Stanford, P., Crowe, M. W., \& Flice, H. (2010). Differentiating with Technology. TEACHING Exceptional Children Plus, 6(4). https://eric.ed.gov/?id=EJ907030

Yudin, M. (2013, May 16). Technology Gives Students with Disabilities Access to College Courses. ED.Gov Blog. https://blog.ed.gov/2013/05/technology-gives-students-with-disabilities-access-to-college-courses/ 